\title{
A four-month-old boy with bilateral undescended testes
}

\section{Sumit Dave MD MSc}

Competing interests:

This article has been peer reviewed.

The clinical scenario is fictional.

Correspondence to: Sumit Dave, Sumit.Dave@lhsc. on.ca

CMAJ 2016. DOI:10.1503 /cmaj.141015
None declared.
A four-month-old healthy boy presents for a well-baby check-up. At the appointment, the parents mention that physical examination when he was a newborn showed bilateral undescended testes and ask what should be done now.

\section{What manoeuvres should be included in the physical examination?}

Physical examination is the key diagnostic manoeuvre in boys with undescended testes and should be performed at all well-baby check-ups for male babies, starting at birth. ${ }^{1}$ The physical examination requires a cooperative baby and a diligent examiner. The child is placed supine, in a frog-legged position, and the examiner uses a gentle palpation technique with warm hands. A bimanual technique is used, with the nondominant hand gently milking or sweeping down the testis along the inguinal canal and preventing its upward movement during the examination, and the other hand palpating the scrotum and groin to identify the testis.

The undescended testis is usually located along the path of normal testicular descent, which is in the inguinal canal or just above the scrotum. Alternatively, the testis may be in an ectopic position in a superficial location near the groin, in the perineum below the scrotum, in the femoral triangle or at the base of the penis. However, if the testis is located in the abdomen or is absent, it will be impalpable during the physical examination. At the conclusion of the examination, the physician should classify the undescended testis as palpable or impalpable and, if palpable, should define its location as suprascrotal, inguinal or ectopic. ${ }^{1}$

The examiner should also determine the location of the urethral meatus, to identify or rule out concomitant hypospadias. Boys with both proximal hypospadias and an undescended testis should be evaluated for an underlying disorder of sexual differentiation. ${ }^{1,2}$ able in Appendix 1, at www.cmaj.ca/lookup/suppl/doi:10.1503/ cmaj.141015/-/DC1.

\section{Does the baby have retractile testes or undescended testes?}

Physical examination is the only modality that allows the clinician to differentiate an undescended testis from a retractile testis. An undescended testis cannot be manipulated into the scrotum despite gentle traction or milking of the gonad during examination of a relaxed child. The hemiscrotum on the side of the undescended testis appears poorly developed and has fewer rugae (or folds) than a hemiscrotum with a descended testis. ${ }^{1}$

In contrast, a retractile testis can be brought down to the scrotum in a relaxed baby; after gentle traction (holding the testis down in the scrotum for 10-20 seconds, to allow fatigue of the cremaster muscle), it usually stays in the scrotum for a short duration once released. ${ }^{1}$ This implies that when the cremasteric reflex is suppressed, the testis is capable of staying down in the scrotum unaided, without manual traction. In most cases of retractile testis, the parents will report confirmatory observations, stating that when the child is relaxed (e.g., after a bath or while sleeping), they can visualize or feel a descended testis in the scrotum.

Boys with an undescended testis should undergo orchidopexy by 18 months of age. ${ }^{1}$ Boys with a retractile testis can be safely followed without surgical intervention, as there is no evidence of testicular damage over time.

In some cases, a retractile testis may undergo secondary ascent to become an undescended testis over time. Therefore, all boys with a retractile testis should undergo an annual physical examination to ensure that the testis remains retractile or that it has descended and has not secondarily become an undescended testis. ${ }^{1}$ The percentage of retractile testes that ascend and require orchidopexy is difficult to reliably estimate; retrospective studies quote a $3 \%$ to $30 \%$ risk in the prepubertal age group. ${ }^{3,4}$

\section{Are any investigations required?}

The use of ultrasonography in boys with an undescended testis is not recommended, as clinical examination remains the key diagnostic tool. ${ }^{1,5,6}$ 
If the testis is palpable on clinical examination, no further radiologic work-up is required before surgical management.

For boys with an impalpable testis, ultrasonography lacks sufficient sensitivity $(45 \%)$ and specificity (78\%) to rule out absence of the testis; therefore, these boys will still need to undergo diagnostic laparoscopic evaluation under general anesthesia. ${ }^{5}$ Currently, there is no radiologic test that can be used to reliably diagnose an absent testis or identify the location of an impalpable testis to preclude any form of surgical exploration. Laparoscopic evaluation of an impalpable undescended testis has almost $100 \%$ sensitivity and specificity in establishing the diagnosis, while allowing surgical treatment to proceed during the same course of anesthesia. ${ }^{1,7}$

Any male newborn with bilateral impalpable undescended testes should be investigated before discharge from hospital to rule out a disorder of sexual differentiation. Endocrinologic work-up (to determine karyotype and levels of serum 17-hydroxyprogesterone, urinary 17-ketosteroids, testosterone, luteinizing hormone, folliclestimulating hormone and müllerian inhibiting substance) should be performed to rule out congenital adrenal hyperplasia or bilateral absent testes. ${ }^{1}$ Untreated congenital adrenal hyperplasia can lead to life-threatening adrenal crisis in the first few weeks of life. Once this disorder has been ruled out, the differential diagnosis in a neonate with bilateral impalpable undescended testes includes a male baby with intra-abdominal testes, anorchia or bilateral vanishing testes.

\section{Does the baby require referral for surgical treatment?}

If the baby has a retractile testis, no referral is required, unless the testis undergoes secondary ascent to become an undescended testis over time, as described above.

Surgical treatment for undescended testis should be performed between 12 and 18 months of age, to maximize fertility potential and to prevent loss of germ cells. ${ }^{1,8} \mathrm{~A}$ single randomized controlled trial comparing testicular growth after orchidopexy indicated that early surgery (at nine months) was followed by catch-up testicular growth, which was not seen after late surgery (at three years) ${ }^{9}$

The risk of testicular cancer may be increased by delayed surgery, but there is no evidence of this difference when orchidopexy is performed in early childhood. However, there is clear evidence that the risk of cancer is lower for boys who undergo prepubertal orchidopexy than for those who undergo postpubertal orchidopexy. ${ }^{10}$ Overall, the relative risk of testicular cancer in undescended testes ranges from 2.75 to 8 , depending on the location of the testis and the age at orchidopexy. ${ }^{11}$

If the clinical examination suggests an undescended testis, and taking current surgical wait times into account, referral to a specialist after three months of age is reasonable. Referral before three months of age is not indicated because there is a chance of spontaneous descent up to this age. ${ }^{12}$

\section{Case revisited}

The physical examination showed bilateral palpable undescended testes. The child was referred to a surgeon by 6 months of age, to allow orchidopexy at 15 months of age.

\section{References}

1. Kolon TF, Herndon CDA, Baker LA, et al. Evaluation and treatment of cryptorchidism: AUA guideline. Linthicum (MD): American Urological Association; 2014. Available: www.auanet.org/ education/guidelines/cryptorchidism.cfm (accessed 2015 Sept. 1).

2. Cox MJ, Coplen DE, Austin PF. The incidence of disorders of sexual differentiation and chromosomal abnormalities of cryptorchidism and hypospadias stratified by meatal location. J Urol 2008; 180:2649-52.

3. Stec AA, Thomas JC, DeMarco RT, et al. Incidence of testicular ascent in boys with retractile testes. J Urol 2007;178:1722-4.

4. Agarwal PK, Diaz M, Elder JS. Retractile testis - Is it really a normal variant? J Urol 2006;175:1496-9.

5. Tasian GE, Copp HL. Diagnostic performance of ultrasound in nonpalpable cryptorchidism: a systematic review and meta-analysis. Pediatrics 2011;127:119-28.

6. Urology: five things physicians and patients should question. Montréal: Canadian Urological Association; 2014. Available: www. choosingwiselycanada.org/recommendations/urology/ (accessed 2015 Sept. 1).

7. Baker LA, Docimo SG, Surer I, et al. A multi-institutional analysis of laparoscopic orchidopexy. BJU Int 2001;87:484-9.

8. Tasian GE, Hittelman AB, Kim GE, et al. Age at orchidopexy and testis palpability predict germ and Leydig cell loss; clinical predictors of adverse histological features of cryptorchidism. $J$ Urol 2009;182:704-9

9. Kollin C, Karpe B, Hesser U, et al. Surgical treatment of unilaterally undescended testes: testicular growth after randomization to orchidopexy at age 9 months or 3 years. J Urol 2007;178:1589-93.

10. Pettersson A, Richiardi L, Nordenskjold A, et al. Age at surgery for undescended testis and risk of testicular cancer. N Engl J Med 2007;356:1835-41.

11. Wood HM, Elder JS. Cryptorchidism and testicular cancer: separating fact from fiction. J Urol 2009;181:452-61.

12. Berkowitz GS, Lapinski RJ, Dolgin SE, et al. Prevalence and natural history of cryptorchidism. Pediatrics 1993;92:44-9.

Affiliation: Departments of Surgery and Pediatrics, Western University, London Health Sciences Centre, London, Ont.

\footnotetext{
Decisions is a series that focuses on practical evidence-based approaches to common presentations in primary care. The articles address key decisions that a clinician may encounter during initial assessment. The information presented can usually be covered in a typical primary care appointment. Articles should be no longer than 650 words, may include one box, figure or table and should begin with a very brief description (75 words or less) of the clinical situation. The decisions addressed should be presented in the form of questions. A box providing helpful resources for the patient or physician is encouraged.
} 